\title{
MEDIAÇÃO ENTRE A ESCOLA E O NOVO MUNDO DO TRABALHO NA FORMAÇÃO DE TÉCNICOS DE NÍVEL MÉDIO
}

\author{
MEDIATION BETWEEN THE SECONDARY SCHOOL AND THE \\ WORKING WORLD IN TECHNICIANS TRAINING IN BRAZIL
}

MEDIACIÓN ENTRE LA ESCUELA SECUNDARIA Y EL MUNDO DEL TRABAJO EN LA FORMACIÓN DE TÉCNICOS EN BRASIL

José dos Santos Souza ${ }^{1}$

Resumo Este artigo tem como objeto de análise a mediação entre a escola e o mundo do trabalho na formação de técnicos de nível médio em instituições de ensino vinculadas à Rede Federal de Educação Profissional, Científica e Tecnológica brasileira que se materializa prioritariamente por meio das atividades de estágio supervisionado. Seu objetivo é explicitar em que aspecto a mediação entre a escola e o mundo do trabalho tem sido pervertida pela lógica mercantil, deslocando a atividade de estágio supervisionado do campo pedagógico para o campo da intermediação de força de trabalho, conferindo-lhe o caráter de trabalho precário. Trata-se de uma pesquisa básica, de análise qualitativa, que apresenta como resultado a distinção das concepções e práticas de estágio supervisionado em duas categorias. A primeira se insere na perspectiva de formação interessada e imediatista e a outra se insere na perspectiva de formação unitária. $\mathrm{O}$ autor aponta a predominância da perspectiva de formação interessada e imediatista nas ações e concepções de mediação entre escola e mundo do trabalho, o que corrompe as atividades de estágio supervisionado, conferindo-lhe características próprias de trabalho precário.

Palavras-chave trabalho e educação; ensino médio; ensino técnico; educação profissional; estágio supervisionado.
Abstract This paper analyzes the mediation between the school and the employment market in the mid-level technical training in Brazilian teaching institutions belonging to the Rede Federal de Educação Profissional, Científica e Tecnológica that materializes mainly through supervised internship activities. The paper's goal is to explain to what extent the mediation between school and employment market has been perverted by market logic, shifting the supervised internship activities of the teaching field to the field of workforce intermediation, giving it precarious job character. This is a basic research, developed by qualitative analysis, pointing as a result the distinction of conceptions and practices internship supervised in two categories. The first categorie is inserted in the pragmatic training perspective and another which is inserted in the omnilateral training perspective. The author points out the predominance of the pragmatic prospect of training in actions and conceptions of mediation between school and the employment market, which corrupts the internship activities supervised, giving it characteristics of precarious work.

Keywords work and education; secondary education; training; professional education; supervised internship. 


\section{Introdução}

Tomamos aqui como objeto de análise as mediações entre a escola e o mundo do trabalho na formação do técnico de nível médio. Nosso propósito é analisar em que aspecto a relação entre a escola e o mundo do trabalho tem sido pervertida pela lógica mercantil, que desloca a atividade de estágio supervisionado do campo pedagógico para o campo da competitividade no mercado de trabalho, conferindo-lhe o caráter de trabalho precário. Talvez esse percurso analítico nos permita explicar com maior propriedade as diferentes configurações que esse tipo de atividade pedagógica pode assumir na atualidade, bem como avaliar as implicações pedagógicas, sociais, políticas e econômicas dessas diferentes configurações.

Nossa referência empírica de análise consiste no trabalho pedagógico desenvolvido em instituições da Rede Federal de Educação Profissional, Científica e Tecnológica (doravante citada simplesmente como Rede Federal), em especial a forma como, nesse trabalho, se desenvolve o estágio supervisionado, uma atividade que materializa as concepções e práticas de mediação entre a escola e o mundo do trabalho na formação do técnico de nível médio. A escolha desta rede de ensino se dá devido ao fato de ela ter se constituído como referência para o ensino técnico de nível médio de todo o país, tendo seu modelo seguido por inúmeras redes de ensino no nível estadual e municipal. A população investigada se circunscreve aos sujeitos envolvidos direta ou indiretamente em atividades de estágio supervisionado desenvolvidas em cursos técnicos oferecidos de modo integrado, concomitante ou subsequente ao Ensino Médio, em cinco instituições de ensino componentes da Rede Federal que, por princípio ético, serão aqui identificadas como: a) IE/Sul; b) IE/Norte-a; c) IE/ Norte-b; d) IE/Nordeste; e) IE/Sudeste. Destas instituições de ensino, foram investigados os seguintes sujeitos: estudantes de cursos técnicos (integrado, concomitante ou subsequente ao ensino médio) considerados aptos a realizar atividade de estágio supervisionado (matriculados nos dois últimos anos do respectivo curso); docentes do Ensino Básico, Técnico e Tecnológico, inclusive aqueles que ocupam cargos de gestão, tais como: Diretor Geral de Campus; Diretor de Ensino; Coordenador Pedagógico; Coordenador do Setor de Estágio; Coordenador de Curso Técnico.

Em relação à categoria 'docentes', de uma população de 423 sujeitos, obtivemos uma amostra composta por 144 deles (34\% do total). Quanto à categoria 'estudantes', de uma população de 1.080 sujeitos matriculados em cursos técnicos ofertados pelas instituições investigadas e aptos a fazer estágio supervisionado, obtivemos uma amostra de 348 deles (32,2\% do total), conforme explicitado na Tabela 1. Estas amostras foram constituídas por aqueles que atenderam ao pedido de preenchimento de formulário eletrônico do Google Drive enviado por e-mail a toda a população investigada. Estes questionários 
ficaram disponíveis para preenchimento durante o período de 02/09/2013 a 24/01/2014, no caso dos docentes; e de 18/11/2013 a 08/08/2014, no caso dos estudantes. Em ambos os casos, tratam-se de amostras probabilísticas, pois cada um dos sujeitos de ambas as categorias que compõem a população investigada teve igual probabilidade de compor a amostra. Em outro aspecto, tratam-se também de amostras casuais simples, pois cada segmento investigado teve oportunidade igual de seus membros serem incluídos na amostra.

Tabela 1

Número de sujeitos investigados e número de respostas ao questionário eletrônico, por instituição de ensino 2015.

\begin{tabular}{ccccccc}
\hline & \multicolumn{3}{c}{ Docentes } & \multicolumn{3}{c}{ Estudantes } \\
\cline { 2 - 7 } Instituição & Total & $\begin{array}{c}\mathbf{N}^{\circ} \text { de } \\
\text { respostas }\end{array}$ & $\%$ & Total & $\begin{array}{c}\mathbf{N}^{\circ} \text { de } \\
\text { respostas }\end{array}$ & $\%$ \\
\hline IE/Norte-a & 130 & 31 & 23,8 & 220 & 58 & 26,4 \\
IE/Norte-b & 44 & 20 & 45,5 & 210 & 62 & 29,5 \\
IE/Nordeste & 76 & 42 & 55,3 & 143 & 46 & 32,2 \\
IE/Sudeste & 80 & 39 & 48,8 & 213 & 67 & 31,5 \\
IE/Sul & 93 & 12 & 12,9 & 294 & 115 & 39,1 \\
Total & 423 & 144 & 34,0 & 1080 & 348 & 32,2 \\
\hline
\end{tabular}

Fonte: Dados coletados pelo autor.

Nota: IE - Instituição de ensino.

Acerca dos instrumentos de coleta de dados e do percurso analítico da pesquisa, esclarecemos que para sistematizar o conceito de estágio supervisionado e suas formas de realização, destacando as orientações pedagógicas que indicam parâmetros para o bom desenvolvimento dessa atividade formativa, nos valemos de análise de fontes bibliográficas secundárias, em especial a legislação brasileira, pareceres do Conselho Nacional de Educação (CNE) e de demais documentos do Ministério da Educação (MEC) e da Secretaria de Educação Profissional e Tecnológica (SETEC). Para avaliar os limites e as possibilidades que a legislação brasileira determina para a atividade de estágio supervisionado, nos valemos de entrevistas semiestruturadas aplicadas, de questionários eletrônicos e do registro de grupos focais. Para analisar as estratégias de estágio supervisionado adotadas pelas instituições pesquisadas, destacando as concepções e práticas docentes que orientam este trabalho pedagógico, nos valemos das entrevistas semiestruturadas e de questionários eletrônicos, além da análise de fontes bibliográficas primárias, tais como registros escolares, Planos de Desenvolvimento Institucional (PDI), Projeto Pedagógico Institucional (PPI), Projetos Pedagógicos de Cursos (PPC), Planos de Gestão etc. Para analisar expectativas de estudantes de cursos técnicos de 
nível médio em relação ao estágio supervisionado, nos valemos dos questionários eletrônicos e do registro de grupos focais. Para verificar se as mudanças no trabalho e na produção determinadas pela crise estrutural do sistema capitalista interferem nas experiências de estágio supervisionado vividas por estudantes de cursos técnicos de nível médio, nos valemos principalmente do registro de grupos focais, embora as entrevistas semiestruturadas e os questionários eletrônicos de docentes e de estudantes tenham nos auxiliado consideravelmente nessa tarefa. Para estabelecer possíveis identidades entre as diferentes formas de realização de 'estágio' e o 'trabalho precário' na atualidade, nos valemos prioritariamente do registro de grupos focais.

\section{Fundamentos teóricos da análise}

As mudanças ocorridas na política pública de formação para o trabalho no Brasil, a partir da segunda metade dos anos 1990, foram bastante significativas. As reformas empreendidas para ajustar o sistema educacional brasileiro com vistas ao atendimento de demandas empresariais para a recomposição das bases de acumulação corroídas pela crise estrutural do capital atingiram tanto a Educação Básica como a Educação Superior, passando pela Educação Profissional e pela Educação de Jovens e Adultos (EJA). No desenvolvimento dessa reforma, a relação entre formação geral e formação técnica profissionalizante ficou mais bem definida, com atribuições e campos de atuação mais bem delimitados, segundo a perspectiva hegemônica do sistema capitalista, conferindo-lhe caráter mais pragmático e racional, na medida em que se pauta em uma espécie de recrudescimento da Teoria do Capital Humano (Souza, 2005). Nesse sentido, a educação profissional atualiza seu caráter interessado e imediatista, vinculando-se de uma vez por todas ao conjunto de políticas públicas de trabalho e renda (Souza, 2013). Isto corrobora a ideologia da qualificação como fator determinante de ingresso e permanência no mercado de trabalho - empregabilidade.

Essas reformas promovidas na formação para o trabalho se inserem no bojo de mudanças substantivas no trabalho, na produção e na mediação do conflito de classes desencadeadas a partir da crise estrutural do capital (Mészáros, 2002; Chesnais, 1996; Harvey, 1992; Antunes, 2000; Anderson, 1995; Alves, 2000). No Brasil, essas mudanças se tornam mais evidentes a partir dos anos 1990, especialmente no governo de Fernando Henrique Cardoso. Do mesmo modo, seus efeitos mais deletérios também se tornam mais evidentes nessa época: flexibilização do trabalho e da produção, desregulamentação dos direitos trabalhistas, combate à livre organização coletiva dos trabalhadores, intensificação da precariedade, desemprego estrutural e acirramento da competitividade e da exclusão social. 
Emerge desse contexto a apologia à sustentabilidade, ao empreendedorismo, à empregabilidade e ao capital social como conceitos-chave para a interpretação da dinâmica do mercado de trabalho e busca de 'soluções' - ou conformação ética e moral da classe trabalhadora - para a ameaça do desemprego estrutural e para a nova realidade do mercado de trabalho. Essa perspectiva de interpretação se institui como ideologia capaz de ofuscar a compreensão da realidade como uma espécie de 'cortina de fumaça', ao mesmo tempo em que aciona nos indivíduos a disposição para o consenso diante das alternativas empresariais de enfrentamento da crise estrutural do capital, do desemprego, em busca de conformidade diante da realidade competitiva e excludente do mercado do trabalho. Trata-se de uma espécie de pedagogia política renovada para formar nos trabalhadores a capacidade de encarar com naturalidade as incertezas e instabilidades que o mundo do trabalho lhes reserva na atualidade. Tudo isto tem sido suficiente para amortizar qualquer tipo de reação organizada dos trabalhadores ao modelo de desenvolvimento hegemônico.

É nesse contexto de mudanças que a prática de estágio supervisionado é conduzida ao status de qualificação profissional imprescindível para ingresso e permanência do jovem no mercado de trabalho e, nesta condição, constitui-se em principal forma de mediação entre a escola e o mundo do trabalho. Muitas vezes, essa atividade é concebida como autônoma e completamente desvinculada de qualquer processo de ensino/aprendizagem. Isto ocorre não necessariamente por se acreditar por si só a experiência do trabalho seja bastante para a formação de um profissional, mas porque tal autonomia, ao imprimir total descompromisso da atividade de estágio supervisionado para com o processo de ensino/aprendizagem, facilita consideravelmente sua deturpação e sua aplicação produtiva, na qual o estagiário substitui um trabalhador, o que pode caracterizar trabalho precário disfarçado em oportunidade de aprendizagem (Martins, 2012; Reis, 2012).

\section{Ações e concepções acerca da mediação entre escola e mundo do trabalho}

O estágio supervisionado é uma prática pedagógica que tem como propósito mediar a relação entre o ambiente escolar e o ambiente do trabalho, de modo a confrontar aspectos teóricos e práticos vivenciados no cotidiano escolar com aqueles vivenciados no espaço produtivo. Tal confronto visa suscitar reflexões que, uma vez sistematizadas, têm efeito pedagógico complementar à formação para o trabalho. Portanto, o estágio supervisionado perde seu sentido pedagógico quando é concebido como atividade produtiva ou mesmo como estratégia de ingresso no mercado de trabalho. Da mesma forma que perde seu potencial de formação humana unitária quando é concebido a partir de uma compreensão da relação entre teoria e prática, como se esses dois elementos fossem dissociáveis, como se existisse a possibilidade de 
separar uma coisa da outra. Pior ainda é quando, ao se estabelecer essa possibilidade, estabelece-se também, entre uma e outra, certa hierarquização, na quala prática é concebida como uma espécie de elemento catalisador da teoria, na medida em que lhe dá validade ou não.

Temos, portanto, duas concepções básicas de estágio supervisionado em disputa. Uma delas parte da premissa de que teoria e prática são indissociáveis e que tanto o ambiente escolar quanto o ambiente produtivo exalam aspectos teóricos e práticos. Portanto, da mesma forma que a reflexão sobre a prática favorece a compreensão do processo de trabalho, praticar o que é refletido e racionalizado também a favorece. De acordo com essa concepção, o ambiente escolar é tão importante quanto o ambiente produtivo, na medida em que enquanto no primeiro a reflexão sobre a prática é sistematizada, no segundo, aquilo que foi refletido e sistematizado no ambiente escolar é colocado em prática. Todavia, em ambos os ambientes, seja ele escolar ou de produção, a teoria e a prática se apresentam em permanente movimento de contradição e síntese que, uma vez racionalizado, se converte em conhecimento, não só profissional, mas científico e/ou filosófico. Dessa forma, o foco do processo pedagógico decorrente da atividade de estágio supervisionado é a própria reflexão acerca das contradições e sínteses entre teoria e prática como elemento formativo do trabalhador. Neste caso, a meta é a formação de um trabalhador não só com capacidade operacional de uma atividade produtiva específica, mas que seja também capaz de compreender a si próprio e a seus pares enquanto seres produtivos, bem como compreender o sentido sócio-histórico da própria produção, a partir de uma consciência reflexiva.

Já a outra concepção de estágio supervisionado parte da compreensão de que há um momento da teoria e outro da prática que ocorrem distintamente, inclusive em ambientes diferentes. Nessa concepção, normalmente, é a prática que realmente importa, pois parte-se do pressuposto de que a reflexão teórica é um estágio que antecede a prática. A partir dessa concepção, o ambiente escolar é entendido como espaço da teoria e o de trabalho é entendido como o da prática. Nesse aspecto, a atividade prática é considerada como aquela em que o conhecimento se consolida, na medida em que se expressa em atividade produtiva, em resultados concretos no processo de geração de valor de troca. Nessa perspectiva, a prática valida ou invalida o que se 'aprendeu' na teoria. Atribui-se, assim, poder absoluto a ela.

Dessa forma, o foco do processo pedagógico proveniente da atividade de estágio supervisionado é a possibilidade de se colocar em prática o que foi aprendido no cotidiano escolar e, também, de se rechaçar outros conhecimentos que, na prática, não encontram efeito produtivo. Justamente por isso a atividade prática é supervalorizada, pois oferece oportunidade de selecionar o que realmente importa para a valorização do capital. Neste contexto, a prática assume status quase sobrenatural, concebida como fundamento e sentido de 
todo o conhecimento. A isto denominamos de fetiche da prática. Neste caso, a meta é a formação de um trabalhador capaz de produzir, e não de pensar sua existência, tampouco de conhecer o sentido sócio-histórico da produção, conformado em uma consciência comum.

Considerando essas duas concepções que se confrontam no ambiente escolar, poderíamos nos reportar à filosofia da práxis de Sanches-Vasquez, quando afirma que "a consciência comum pensa os atos práticos, mas não faz da práxis - como atividade social transformadora - seu objeto; não produz - nem pode produzir, (...) - uma teoria da práxis" (1977, p. 10). Nesse sentido, poderíamos associar a concepção de estágio supervisionado própria dos interesses históricos originados da organização e luta dos trabalhadores ótica do trabalho - como sendo de natureza científica e filosófica de formação humana, no nível da teoria da práxis, de caráter unitário; enquanto a outra, própria dos interesses históricos da ordem burguesa de produção e reprodução social da vida material - ótica do capital -, como uma concepção de natureza prática e imediatista de formação humana, no nível da consciência comum, de caráter instrumental e pragmático. De acordo com essa distinção (Sánchez-Vázquez, 1977), a consciência comum não percorre a distância que a separa da consciência reflexiva, por isso não é transformadora, não é criadora, portanto, jamais revolucionária. Para isto, a consciência comum precisa ser superada para que haja possibilidade de transformação criadora da realidade, num sentido revolucionário:

O homem comum e corrente se considera a si mesmo como o verdadeiro prático; é ele que vive e age praticamente. Dentro de seu mundo as coisas não apenas são e existem em si, como também são e existem, principalmente, por sua significação prática, na medida em que satisfazem necessidades imediatas de sua vida cotidiana. Mas essa significação prática se lhe apresenta como imanente às coisas; ou seja, apresentando-se nelas, independente dos atos humanos que lhes conferem tal significação. As coisas não apenas são conhecidas em si, à margem de toda atividade humana - ponto-de-vista do realismo ingênuo -, como também significam por si mesmas; isto é, ignora que pelo fato de significar, de ter uma significação prática, os atos e objetos práticos só existem pelo homem e para ele. O mundo prático - para a consciência comum - é um mundo de coisas e significações em si (Sánchez-Vásquez, 1977, p. 11).

Em nosso entendimento, é justamente na hegemonia da concepção de estágio supervisionado pautada na perspectiva de formação do homem prático, percebida no ambiente das instituições de ensino investigadas, que reside a precariedade dessa atividade como estratégia pedagógica de formação para o trabalho. Em síntese, poderíamos afirmar que a precariedade da atividade de estágio supervisionado se estrutura exatamente na visão que concebe a 
prática como fetiche, como se a prática por si só fosse o sentido da atividade laboral. Para maior compreensão dessa precariedade, explicitaremos como ela se expressa a partir de dois diferentes aspectos.

A mediação entre escola e mundo do trabalho no cotidiano de uma instituição de ensino técnico profissionalizante de nível médio se materializa prioritariamente por meio das atividades de estágio supervisionado que devem complementar a formação profissional. Nesse aspecto, a análise dos dados aponta para a ausência de qualquer compreensão desse componente curricular como atividade complementar à formação profissional por parte dos sujeitos investigados. Essa constatação é frequentemente expressa pelo entendimento meramente burocrático da função do Setor de Estágio Supervisionado das instituições investigadas, como se tal atividade se encerrasse no controle de cadastro de estudantes em exercício do estágio e de contratos de empresas concedentes. $\mathrm{O}$ acompanhamento pedagógico, se é que se pode chamar assim, nessa perspectiva, fica reduzido a mero controle de registro de relatório de estágio, sem qualquer função formativa. Assim, a mediação entre a escola e o mundo do trabalho se reduz a uma função meramente protocolar, na qual um determinado setor da instituição de ensino - nesse caso o Setor de Estágio Supervisionado - gerencia documentos que referenciam uma determinada relação entre estudantes, empresas concedentes e orientadores de estágio. Esta perspectiva é muito bem expressa na definição que um dos coordenadores de estágio entrevistados faz acerca de sua função:

O coordenador de estágio, ele faz aquela integração entre escola/empresa, ele mantém atualizado o cadastro é... Das empresas parceiras, ele cuida da parte burocrática do estágio, de convênio, do termo de compromisso, encaminha algum estagiário para o mercado de trabalho e orienta os estagiários no preen... Quanto ao preenchimento dos formulários (Coord. de Estágio/IE-Nordeste)

Mesmo quando existe a pretensão de que a gestão da atividade de estágio supervisionado se constitua um instrumento formativo que vislumbre algum tipo de reflexão da prática, mediada por contradições, capaz de permitir ao estudante a construção de conhecimento útil para sua formação profissional, prevalece a ausência de mecanismos eficazes para que isto ocorra. Uma evidência disto está nos seguintes depoimentos, quando coordenadores de estágio definem sua função:

Acho que o acompanhamento, é... O contato com as empresas, a busca de convênios e esse contato... É o acompanhamento dos alunos através de visitas às empresas, da supervisão do professor, esse retorno que o aluno também dá de como foi o estágio, ele mesmo fala, é : “- eu gostei, ou então, eu não gostei, essa é uma 
empresa legal" . O próprio aluno dá esse retorno e é bom para os próximos (Coord. de Estágio/IE-Sudeste).

O coordenador de estágio, ele se preocupa em fazer a integração entre escola e empresa, não é? Além disso, ele também tem a responsabilidade de planejar estrategicamente o funcionamento, 'né?', de todo o processo que se dá no estágio, desde a visita técnica na empresa é.. Acompanhado de um técnico do... Da área, 'né?', do curso, especificamente do curso, e depois ele vai acompanhar esse processo é... Juntamente com as coordenações de curso 'né?', explicando a ela... A elas que há a necessidade de ter um orientador, um professor orientador e esse professor orientador é em conjunto com a própria Coordenação de Curso tem que saber como é que se dá todo o processo de estágio desde a assinatura do termo de compromisso, 'né?', e após isso, o aluno, ele tem suas fichas de avaliação 'né', é que vai ter que ser preenchidas pelo professor orientador, pelo é... Supervisor da empresa, o aluno também tem esse acompanhamento dentro da empresa e ele também tem é... Que fazer o seu plano de estágio, que é uma das primeiras coisas que ele tem que fazer, ter noção do quê que ele vai fazer lá dentro da empresa. Então, plano de estágio... Ele tem que fazer relatórios de estágio também, particularmente eu estou cobrando dele é... Um relatório mensal 'né?', mensalmente o aluno tem que entregar e como são 200 horas a carga horária é... Praticamente dois em dois meses, quatro horas diárias, 20 horas semanais, dá para ele cumprir a carga horária dele é... Tranquilamente, entregando como dois meses, entregando dois relatórios mensais. Também a gente, nesse processo, procura acompanhar esse aluno quando ele conclui o estágio, que nós chamamos de aluno egresso, e como é esse acompanhamento? A gente aplica um questionário com eles, um questionário de estágio no final do estágio. Eles entregam esse questionário e a gente vai ter noção de como que foi, qual é a visão dele do estágio 'né?', para que a gente possa até melhorar mais ainda essa relação entre a empresa e o instituto (Coord. de Estágio/IE-Norte-A).

Em contrapartida, quando observamos o trabalho desenvolvido pelas coordenações de pedagógicas das instituições investigadas, chamou-nos a atenção o fato de nenhum dos coordenadores pedagógicos ter mencionado qualquer referência ao estágio supervisionado, ao definirem sua função institucional. Transcrevemos aqui a definição de cada um deles acerca da função de um coordenador pedagógico:

(...) Propõe projetos, é... Que possam auxiliar no processo ensino-aprendizagem... É... Direciona reuniões com professores e alunos... Orienta o trabalho dos professores a partir das dificuldades encontradas ao longo do período, 'né?', faz intervenções também com os alunos... Na verdade eu... Eu faço um pouquinho do trabalho de orientadora educacional também, pela redução da equipe. Então, como 
eu sou concursada para cá como orientadora educacional, não consegui... É... Me desvincular dessa função. Então, eu faço a parte de Coordenação Pedagógica e de orientação dos alunos também (Coord. Pedagógica/IE-Sudeste).

Na minha concepção, a principal atividade dele é acompanhar o processo de ensino-aprendizagem. É orientando, é... E redirecionando estratégias para que esse processo possa acontecer da melhor forma possível e tendo o principal foco o aluno (Coord. Pedagógica/IE-Nordeste).

O próprio nome já é sugestivo na resposta, 'né?', coordena todas as atividades pedagógicas da instituição, desde uma simples elaboração de calendário acadêmico, como reformulação de planos de curso, intervenções didático-pedagógicas na medida que necessário, atendimento a discentes, atendimento aos docentes, verificação do nível de aprendizagem, hã... Dados referentes a exames nacionais do ensino médio, 'né?', e outros dados importantes de se estar no dia a dia de trabalho (Coord. Pedagógica/IE-Sul).

(...) entre as várias atribuições do coordenador pedagógico, está também a de assessorar e acompanhar os trabalhos pedagógicos das coordenações de cursos técnicos. Então, tem diferença da nossa instituição para as outras escolas. E busca também o aperfeiçoamento da prática pedagógica (Coord. Pedagógica/IE-Norte A).

Bem, o coordenador, ele trabalha com todos os processos de ensino/aprendizagem. Seja ele evasão, acompanhamento de professor, planejamento, 'né?', análise de avaliação escolar é... Acompanhamento das atividades docentes, acompanhamento das atividades dos discentes e também a relação família/escola (Coord. Pedagógica/IE-Norte B).

Embora seja notório que o estágio supervisionado não está vinculado às respectivas coordenações pedagógicas em nenhuma das instituições investigadas, não deixa de ser curioso o fato de os coordenadores pedagógicos não mencionarem qualquer relação com esta atividade, mesmo que indiretamente. Além disto, não podemos deixar de pontuar certa indefinição do que exatamente faz um coordenador pedagógico nessas instituições. $O$ fato é que este é um campo fértil para o desenvolvimento das atividades de estágio supervisionado sem qualquer reflexão crítica da prática vivida, de modo a propiciar que a reflexão da prática, uma vez desenvolvida de forma orgânica à reflexão teórica, possa constituir-se em elemento formativo complementar à formação profissional do técnico de nível médio. 
No que tange aos estudantes, também se percebe distanciamento da compreensão do estágio supervisionado como uma experiência formativa de caráter unitário. É notória a visão imediatista e pragmática que predomina entre eles, além de perceptível desconhecimento do potencial formativo acerca dessa atividade. Na percepção dos estudantes, é mais frequente a ideia simplista de que é uma atividade prática monitorada. Outra ideia também frequente é de que se trata de uma oportunidade de colocar em prática o que foi aprendido na instituição de ensino. A ideia de que o estágio supervisionado é uma oportunidade de aquisição de atributos de empregabilidade também é bastante frequente.

\section{Gráfico 1}

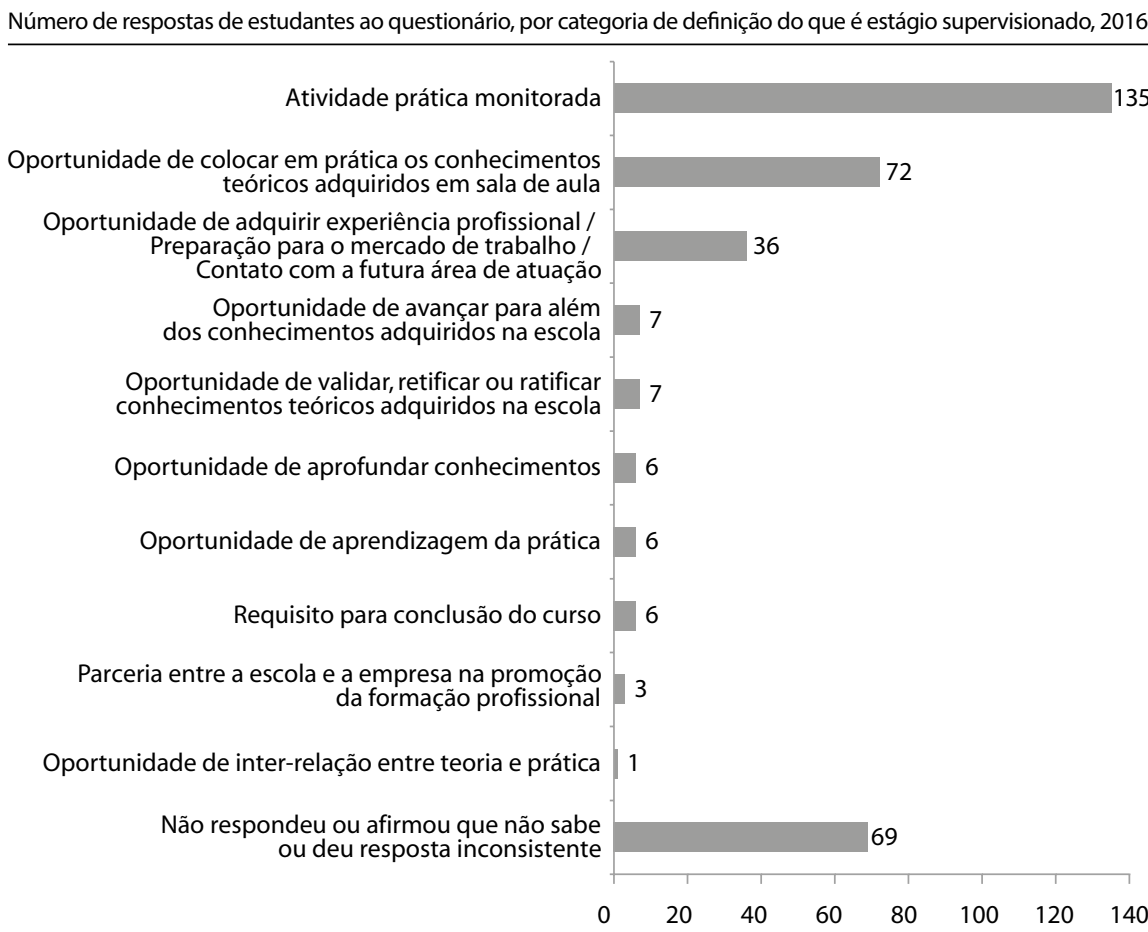

Fonte: Dados coletados pelo autor.

Quando questionados sobre o que é estágio supervisionado, 19,8\% dos estudantes abordados não sabiam ou não tinham ideia clara do que seja. Embora também inconsistente, chamou-nos a atenção o entendimento de $38,8 \%$ dos estudantes de que o mesmo seria uma atividade prática monitorada por algum docente ou profissional da área que acompanha o desempenho do estudante. Observe-se também que 20,7\% dos estudantes compreendem esse momento de sua formação como uma oportunidade de colocar em prática os conhecimentos adquiridos no ambiente escolar, pressupondo a teoria e a prá- 
tica como elementos dissociados no processo de construção do conhecimento profissional. Ainda temos 10,3\% de estudantes que o concebem como uma oportunidade de ingresso no mercado de trabalho, na medida em que essa atividade pode lhe proporcionar maior conhecimento da área de atuação, acúmulo de experiência profissional e, talvez, oportunidade de estabelecer relações interpessoais que lhes favoreçam, diante da possibilidade de efetivação como futuro funcionário da empresa concedente. Nesse sentido, algumas respostas são sintomáticas:

[Estágio supervisionado é] Muito importante, pois é onde temos contato pela primeira vez com o mercado de trabalho e com a vida de um profissional na área da informática, tendo melhor aprendizado e podendo comparar o conhecimento aprendido no curso (...) (Estudante da IE/Sul).

O estágio supervisionado é uma forma de preparação do estudante para o mercado de trabalho. O estudante fica em contato direto com o ambiente de trabalho, desenvolvendo um papel profissionalizante, programado ou projetado, com duração e supervisão constante de leis e normas (Estudante da IE/Norte-A)

[Estágio supervisionado] é um caminho para o mercado de trabalho (Estudante da IE/Norte-A)

Estágio supervisionado é uma forma de aprender muito sobre a área em que se está ou que atuará, além de colocar em prática o que aprendemos na escola, e podermos ver como é o mercado de trabalho, como é trabalhar, ter o primeiro salário, o primeiro emprego, chefe etc. (Estudante da IE/Sul).

[Estágio supervisionado é] Uma oportunidade de conhecer o dia a dia de uma empresa e ter a primeira experiência no mercado de trabalho (Estudante da IE/ Sudeste).

Estas ideias predominantes nas respostas dos estudantes acerca do estágio supervisionado têm como fundamento a dissociação entre teoria e prática. Não ocorre entre eles a compreensão de que tanto o ambiente escolar quanto o ambiente produtivo são espaços de teoria e de prática, de modo que, durante tal atividade, as contradições e sínteses entre teoria e prática são o elemento formativo. Na compreensão dos estudantes, o foco é a possibilidade 
de se colocar em prática o que foi aprendido no ambiente escolar. Entretanto, esta ideia ainda é reforçada por uma outra: a de que se deve rechaçar todo conhecimento que não têm efeito produtivo.

[Estágio supervisionado] É um passo muito importante para a sua carreira profissional, porque você acaba vivenciando não só a teoria, mas principalmente a prática, porque é a partir desta que você percebe se os conhecimentos e ensinamentos ao longo do curso foram de grande valor no início da sua carreira profissional (Estudante da IE/Sudeste).

Entre os estudantes, o momento da prática é supervalorizado e assume status de real sentido de todo o conhecimento profissional, o que materializa entre eles o fetiche da prática, em que a formação profissional é entendida como instrumental para ser capaz de produzir e não de pensar sua existência ou conhecer o sentido sócio-histórico da produção.

\section{A título de conclusão}

Enfim, a partir da análise empreendida, percebemos que apesar de existirem concepções distintas que se enfrentam no cotidiano das instituições de ensino investigadas - que poderiam ser categorizadas como aquelas da perspectiva interessada e imediatista e aquelas da perspectiva de formação unitária do trabalhador -, as concepções de caráter interessado e imediatista são hegemônicas e, portanto, são elas que norteiam a realização das atividades de estágio supervisionado na formação do técnico de nível médio. Assim, o que caracteriza essas atividades nas instituições investigadas, de fato, é o fetiche da prática, o que, em última análise, é o que determina o tipo de mediação entre a escola e o mundo do trabalho empreendido por essas instituições. Tal perspectiva parte da cisão entre teoria e prática, e o momento da prática é o que realmente importa. A partir dessa perspectiva, o ambiente escolar é entendido como o da teoria e o ambiente de trabalho como o da prática. O momento da prática na formação do técnico de nível médio concretizado pelo estágio supervisionado, nessa perspectiva, consolida o conhecimento profissional, na medida em que dá validade ou não àquilo que se aprendeu no ambiente escolar - a teoria. O sentido dessa atividade formativa, nesse aspecto, é a possibilidade de se colocar em prática o que realmente interessa para o ambiente de trabalho, de modo a rechaçar outros conhecimentos que, na prática, não importam. Isto dá real sentido ao que Gramsci (2000) denomina de saber interessado ou ao que Sanches-Vásquez (1972) denomina de consciência comum, o saber do homem prático. 
Em decorrência dessa perspectiva, a dinâmica do estágio supervisionado nas instituições de ensino investigadas se desenvolve carente de uma visão unitária do conhecimento e da gestão desse conhecimento. Justamente por conta do fetiche da prática como elemento norteador do desenvolvimento dessas atividades, sua gestão se dá no sentido de conformar ética e moralmente o estudante às demandas do mercado de trabalho, sempre buscando orientá-los para a empregabilidade, ou seja, para tornarem-se competitivos, na medida em que atendam aos interesses empresariais. Sem qualquer reflexão crítica dessa realidade que demande a superação da consciência comum, a gestão das atividades de estágio fica reduzida a uma prática protocolar de contratos e registros de atividades, de modo que a mediação entre a escola e o mundo do trabalho se dá prioritariamente por meio de instrumentos burocráticos, mesmo quando tal mediação exige o contato entre sujeitos institucionais e sujeitos empresariais.

Ao que tudo indica, o processo de reestruturação produtiva vivido pelas empresas não foi o que determinou a hegemonia da perspectiva interessada e imediatista no tratamento das atividades de estágio supervisionado, embora esse fenômeno tenha intensificado consideravelmente as contradições que tais atividades comportam. A análise dos dados nos leva a crer que o fetiche da prática sempre foi o elemento norteador da condução de qualquer estratégia de mediação entre a escola e o mundo do trabalho em todas essas instituições investigadas. Talvez o que há de novo seja apenas a dinâmica atual do mercado de trabalho e o surgimento de novas demandas de qualificação profissional, mas nada que exija dessas instituições qualquer tipo de superação do fetiche da prática como elemento estruturante da mediação entre a escola e o mundo do trabalho. Portanto, o processo de reestruturação produtiva, na prática, não só intensificou a escassez de vagas de estágio supervisionado, bem como aumentou a probabilidade de a atividade de estágio supervisionado ser pervertida em atividade produtiva para a empresa, assumindo a forma de contratação precária de força de trabalho minimamente qualificada a baixo custo - algo completamente afinado com as estratégias da Lean production e da flexibilização do trabalho e da produção. Como as experiências de estágio supervisionado em todas essas instituições têm como marca comum a precariedade, tanto no que diz respeito a seu desenvolvimento enquanto prática pedagógica quanto no que tange à gestão dessas atividades, poderíamos considerar que o processo de reestruturação produtiva só veio a acirrar ainda mais as contradições inerentes ao desenvolvimento dessas atividades na formação de técnicos de nível médio.

Considerando a realidade de todas as instituições investigadas, é possível afirmar a evidência de condições em que a prática do estágio supervisionado é deturpada, rompendo com seu potencial pedagógico na formação de técnicos de nível médio. A principal característica dessa deturpação é que as coor- 
denações de estágio, unanimemente, compreenderem a atividade de estágio supervisionado como uma oportunidade de experiência profissional que se constitui atributo de empregabilidade. Assim, a experiência de estágio é entendida como uma espécie de primeiro emprego ou, ainda, como oportunidade de estabelecimento de vínculos interpessoais que possam garantir ao estudante o ingresso no mercado de trabalho. Nesse aspecto, pode-se considerar que, nas condições em que a prática do estágio supervisionado se desenvolve nas instituições investigadas, é comum o rompimento do potencial pedagógico dessa atividade na formação de técnicos de nível médio, o que permite considerar certa conformação em torno da concepção das atividades de estágio supervisionado como forma de inserção precária do estudante nos quadros de força produtiva da empresa concedente. Se isto não ocorrer, certamente não será por causa da intervenção da instituição de ensino, apesar de todo o seu controle burocrático sobre o desenvolvimento dessas atividades.

Enfim, concluímos nossa pesquisa com uma dúvida. A análise empreendida nos permite apontar pelo menos seis características em comum verificadas na prática pedagógica de todas as instituições de ensino investigadas, são elas: a) predominância da opinião de que o estágio supervisionado é uma atividade de extrema relevância para a formação do técnico de nível médio; b) definição do estágio supervisionado como atividade curricular obrigatória; c) dificuldades para garantir oportunidades de vaga de estágio supervisionado para seus alunos; d) dificuldade para garantir a efetividade do trabalho de orientação do estágio supervisionado e devido acompanhamento dessa atividade junto à empresa contratante; e) predominância do fetiche da prática como elemento orientador da atividade de estágio; f) dificuldade para avançar de uma concepção interessada e imediatista de estágio supervisionado, que conforma para a consciência comum, para uma concepção de estágio supervisionado que vise à formação para a consciência reflexiva, voltada para a transformação criadora da realidade vivida. Diante de todas essas características comuns, fica evidente o caráter precário do desenvolvimento da atividade de estágio. Isso nos permite, inclusive, identificar, nesse conjunto de atividades, possibilidades bastante favoráveis para que as empresas pervertam a atividade de estágio supervisionado em atividade produtiva, na medida em que concretiza uma espécie de contratação precária de força de trabalho, disfarçada em contrato de atividade de estágio. Diante dessa realidade, questionamos se de fato o estágio supervisionado é uma experiência crucial na formação do técnico de nível médio, a ponto de condicionar sua certificação. Tendemos a acreditar que, na forma como esse tipo de atividade se desenvolve nas instituições investigadas, talvez fosse melhor, para a formação do técnico de nível médio, que sequer existisse. 
Resumen En este artículo se analiza la mediación entre la escuela y el mundo laboral en la formación técnica de nivel medio en las instituciones educativas vinculadas a la Rede Federal de Educação Profissional, Científica e Tecnológica brasileña que se materializa principalmente a través de actividades prácticas supervisadas. Su objetivo es explicar de qué modo la mediación entre la escuela y el mundo del trabajo ha sido pervertido por la lógica mercantil, moviendo la actividad de entrenamiento supervisado del campo de la enseñanza profesional para el campo de intermediación de fuerza de trabajo, que le da el carácter de trabajo precario. Se trata de una investigación básica, de análisis cualitativo, cual apunta la distinción de los concepciones y prácticas de entrenamiento supervisado en dos categorías, un que se inserta en la perspectiva de formación interesada y inmediatista y otro que se inserta en la perspectiva de formación omnilateral. El autor señala el predominio de la perspectiva de formación interesada e inmediatista en las acciones y concepciones de mediación entre la escuela y el mundo del trabajo, el que corrompe las actividades de entrenamiento supervisado, dándole características del trabajo precario.

Palabras clave trabajo y educación; escuela secundaria; formación técnica; educación profesional; entrenamiento supervisado.

\section{Notas}

${ }^{1}$ Universidade Federal Rural do Rio de Janeiro, Instituto Multidisciplinar, Departamento de Educação e Sociedade, Nova Iguaçu, Rio de Janeiro, Brasil. <jsantos@ufrrj.br>. Correspondência: Universidade Federal Rural do Rio de Janeiro, Instituto Multidisciplinar, Rua Savério José Bruno, s/n, Moquetá, CEP 26020-740, Nova Iguaçu, Rio de Janeiro, Brasil.

${ }^{2}$ Estão inclusos na categoria 'docentes' alguns profissionais que não atuam como professores, mas exercem atividades ligadas à organização do trabalho pedagógico. Esta decisão se ampara na concepção que considera a docência não restrita ao trabalho em sala de aula, mas que se estende ao seu planejamento e a sua gestão. Nesta perspectiva, os pedagogos e os técnicos em assuntos educacionais, que nessas instituições são enquadrados como técnicos administrativos de nível superior, foram considerados em nossa pesquisa como profissionais docentes. Além desses, também foram incluídos nesta categoria alguns outros técnicos administrativos que, embora não ocupem a função de pedagogo ou técnico em assuntos educacionais, estão diretamente envolvidos na gestão das atividades de estágio supervisionado. Em todo caso, este contingente não chega a ser expressivo, de modo que não ultrapassa $2 \%$ da categoria 'docentes'.

${ }^{3}$ Quando nos referimos ao caráter interessado da educação, queremos nos reportar à determinada concepção curricular pragmática e racionalista que visa focar o processo educativo para a atividade produtiva que o modelo de desenvolvimento vigente necessita. Nessa perspectiva, o sujeito deve ser formado para dominar conhecimentos e habilidades específicas para uma atividade produtiva determinada. Assim, os métodos e os recursos didáticos são acionados sem qualquer preocupação com a formação do sujeito para além de sua função produtiva. Não há preocupação em articular organicamente a formação para o trabalho com a científica, tampouco com aspectos sociais, políticos e econômicos que permitem ao sujeito cognoscente a apropriação do conhecimento de si próprio e de seus semelhantes como sujeitos históricos. Esta concepção político-pedagógica está mais bem explicada em Souza (2002). 
4 Por 'empregabilidade', entendemos ser “(...) a capacidade de o indivíduo manter-se ou reinserir-se no mercado de trabalho, denotando a necessidade de o mesmo agrupar um conjunto de ingredientes que o torne capaz de competir com todos aqueles que disputam e lutam por um emprego" (Oliveira, 2009).

${ }^{5}$ Quando a atividade de estágio supervisionado se dá em forma de trabalho produtivo com vínculo precário disfarçado em contrato de estágio supervisionado ou quando é concebida como primeiro emprego, para fins de acúmulo de experiência profissional para garantir empregabilidade, ela não deixa de ser formativa, afinal, toda experiência humana o é, para o bem e para o mal. Entretanto, nessas condições, a atividade de estágio supervisionado perde seu caráter pedagógico, na medida em que não corresponde a um plano de ensino/aprendizagem prescrito, com intencionalidade, objetivos e metas explicitamente definidos para este fim. O que se percebeu durante a pesquisa é que, quando esta deturpação da atividade de estágio supervisionado ocorre, é por meio de um estancamento entre o planejamento pedagógico e o efetivo trabalho docente dele decorrente e a realidade a que o estudante é submetido; e isto rompe definitivamente com a relação intrínseca entre o plano de ensino, a prática docente, a experiência pedagógica do estudante e o registro acadêmico do desempenho como referência de conclusão do processo. Uma vez ocorrido este estancamento, a experiência vivida pelo estudante nessas condições citadas torna-se irregular, distinta daquela que está prescrita, configurando inclusive uma deturpação ou mesmo um rompimento, consciente ou não, com os propósitos pedagógicos da atividade de estágio supervisionado, o que configura infração aos dispositivos regulatórios constantes na legislação vigente. A atividade de estágio supervisionado quando é pervertida, portanto, perde seu conteúdo pedagógico para instituir-se como atividade produtiva irregular, assumindo inclusive função formativa enquanto experiência, mas não pedagogicamente instituída.

\section{Referências}

ALVES, Giovanni. O novo (e precário) mundo do trabalho: reestruturação produtiva e crise do sindicalismo. São Paulo: Boitempo, 2000. $365 \mathrm{p}$.

ANDERSON, Perry. Balanço do neoliberalismo. In: SADER, Emir.; GENTILI, Pablo. (orgs.). Pós-neoliberalismo: as políticas sociais e o Estado democrático. Rio de Janeiro: Paz e Terra, 1995. p. 9-23.

ANTUNES, Ricardo. Os sentidos do trabalho: ensaio sobre a afirmação e a negação do trabalho. 3. ed. São Paulo: Boitempo, 2000. 258 p.

CHESNAIS, François. A mundialização do capital. Tradução de Silvana Finzi Foa. São Paulo: Xamã, 1996. 336 p.
GRAMSCI, Antonio. Cadernos do cárcere: os intelectuais. O princípio educativo. Jornalismo. v. II. Tradução de Carlos Nelson Coutinho. Rio de Janeiro: Civilização Brasileira, 2000. [334 p.].

HARVEY, David. Condição pós-moderna. 14. ed. São Paulo: Loyola, 1992. 349 p.

MARTINS, Sergio P. Estágio e relação de emprego. 3. ed. São Paulo: Editora Atlas, 2012. 121 p.

MÉSZÁROS, Istvan. Para além do capital: rumo a uma teoria da transição. Tradução de Paulo César Castanheira e Sérgio Lessa. São Paulo: Boitempo; Campinas: Edunicamp, 2002. 1.103 p. 
OLIVEIRA, Ramon. Empregabilidade. In: PEREIRA, Isabel B.; LIMA, Julio C. F. (orgs.) Dicionário da educação profissional em Saúde. 2. ed. rev. ampl. Rio de Janeiro: Escola Politécnica de Saúde Joaquim Venâncio; Fundação Oswaldo Cruz, 2008. 478 p. Disponível em: $<$ http://www.sites.epsjv.fiocruz.br/dicionario/index.html>. Acesso em: 16 mar. 2017.

REIS, Jair T. Relações de trabalho: estágio de estudantes. 2. ed. São Paulo: LTr, 2012. 194 p.

SÁNCHEZ-VÁZQUEZ, Adolfo. Filosofia da práxis. Tradução de Luiz Fernando Cardoso. 2. ed. Rio de Janeiro: Paz e Terra, 1977. 454 p.

SOUZA, José S. A educação profissional no contexto da reengenharia institucional da política pública de trabalho, qualificação e geração de renda: novos e velhos mecanismos de manutenção da hegemonia burguesa no governo FHC. Trabalho Necessário, v. 11, n. 16, p.1-36, jan.-jun. 2013.

SOUZA, José S. O recrudescimento da Teoria do Capital Humano. In: COLÓQUIO MARX E ENGELS, 4., Campinas, 2005. Anais... Campinas: CEMARX/IFCH, 2005.

SOUZA, José S. Trabalho, educação e sindicalismo no Brasil: anos 90. Campinas: Autores Associados, 2002. 223 p. Cap. I.

Recebido em 25/03/2016. Aprovado em 16/03/2017. 